\section{Improving economic contribution analyses of local agricultural systems: Lessons from a study of the N ew York apple industry}

Todd M. Schmit ${ }^{*}$ and Roberta M. Severson ${ }^{\text {a }}$ Cornell University

Jesse Strzok ${ }^{b}$

Cornell Cooperative Extension

Jose Barros ${ }^{\mathrm{a}}$

Cornell University

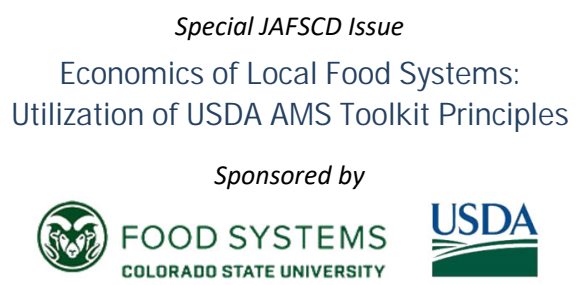

Special JAFSCD Issue

COLORADO STATE UNIVERSITY

Submitted March 26, 2018 / Revised O ctober 3, October 28, and November 7, 2018 /

Accepted November 8, 2018 / Published online January 16, 2019

Citation: Schmit, T. M., Severson, R. M., Strzok, J., \& Barros, J. (2019). Improving economic

contribution analyses of local agricultural systems: Lessons from a study of the New York apple

industry. Journal of A griculture, F ood Systems, and C ommunity D evelopment, 8(Suppl. 3), 37-51.

https:/ / doi.org/ 10.5304/ jafscd.2019.08C.009

Copyright (C) 2019 by the Authors. Published by the Lyson Center for Civic Agriculture and Food Systems. Open access under CC BY license.
Abstract
Policymakers and economic development profes- sionals are often confronted with fundamental questions about the efficacy of agriculture-based economic development initiatives in enhancing the economic vitality of communities relative to other forms of development. By better understanding the relationships of agricultural industries within local
a Charles H. Dyson School of Applied Economics and Management, Cornell University; Warren Hall; Ithaca, NY 14853 USA.
b Eastern New York Commercial Horticulture Program, Cornell Cooperative Extension; 415 Lower Main Street; Hudson Falls, NY 12839 USA.
* Corresponding author: Todd M. Schmit, Associate Professor, Charles H. Dyson School of Applied Economics and Management, Cornell University; 350A Warren Hall; Ithaca, NY 14853 USA; +1-607-255-3015; TMS1@ cornell.edu
economies, community educators, industry leaders, and public officials can make more informed choices to enhance economic activity and impact. We illustrate a framework for conducting multi- industry economic contribution analyses to inform practitioners on what it is, when it should be used,

\section{Funding Disclosure and Acknowledgements}
This work was supported by a grant from the New Y ork Apple Association (NYAA). We are thankful for their assistance in data collection, member communications, and review of prior versions of this manuscript. Additional support was provided by Matt Wells (Lake O ntario Fruit Program), Lindsey Pashow (Harvest NY), Cornell Cooperative Extension; Jenn Smith (New Y ork Cider Association); and Frederick C. Tamarkin (Cornell University). The authors have no financial interest or benefit from the direct application of this research. The views expressed are the authors' and do not necessarily represent the policies or views of any sponsoring firms or agencies. All errors remain our sole responsibility. 
and what information it can provide. As these types of analyses are popular among industry and public agencies alike, promoting a replicable framework improves the compatibility and comparison of analyses across industries, geographies, and time. In addition, we describe the costs and rewards of primary data collection to support more refined and locally-specific impact estimates and illustrate its use to the apple industry in New York State. Finally, we describe how backward industry linkages lead to commonly referenced multipliers. In doing so, practitioners can better understand the local supplying industries that are most important to the industry of inquiry and the supplying sectors most influenced by industry expansion efforts.

\section{Keywonds}

Agricultural D evelopment, Input-O utput Analysis, Multi-Industry Economic Contribution, Economic Multipliers, Local Food Systems Toolkit

\section{Introduction and Literature Review}

Policymakers and economic development professionals are often confronted with fundamental questions about the efficacy of agriculture-based economic development initiatives in enhancing the economic vitality of communities relative to other forms of development. What are the economic impacts of alternative development options, how should the impacts be measured, and what matters most are common questions. If the economic impacts of agriculture-based development are comparable to or exceed non-agriculture-based efforts, it makes sense that they be 'at the table' when evaluating alternative opportunities. That said, a careful understanding and interpretation of economic impacts are required for informed decision-making.

Take, for example, a policy decision directed towards the expansion of alternative manufacturing industries. If policy foci center on targeting development efforts to industries with the largest multiplier effect on jobs, attention to the milk manufacturing and flour milling sectors in New York State (NYS) would be appropriate as both have similar and relatively high jobs multipliers of around six (IMPLAN, 2016). It is worth noting that NYS has a large dairy farming industry but a relatively small amount of wheat production. So why do the milk manufacturing and flour milling sectors have a similar jobs multiplier? A jobs multiplier of six implies that for every job created directly, an additional five jobs are created in backward linked local industries. However, the total number of jobs created is also dependent on the size of the industry expansion. Specific to NYS, 0.6 jobs are required in flour milling for every million dollars of output, while every million dollars of fluid milk sales requires 1.3 direct jobs (IMPLAN, 2016). In other words, to reach the same level of total job creation, the size of industry expansion in flour milling would need to be over twice that of fluid milk manufacturing. ${ }^{1}$

Furthermore, it is important to emphasize that the size of the multipliers says nothing about the likelihood or means by which the primary industries can be expanded. The likelihood of the expansion of a given sector depends on where markets are expanding and the extent to which these sectors are the ones in which the multipliers are large (Schmit \& Boisvert, 2014). Indeed, an equivalent impact could be achieved by supporting the industries that supply those that are targeted for expansion thereby increasing local purchases and the size of the expanding industry's economic multipliers. In short, development alternatives need to consider the local generative effects, the availability and expansion potential of locally procured inputs, and the absolute size of the industry expansion.

Numerous agriculture-based economic contribution analyses can be found online and conducted by various academic, government, industry, and consulting agencies. Several Land G rant universities have estimated the economic contribution of agriculture for their states, albeit with varied definitions of agriculture and/ or the analytical

\footnotetext{
${ }^{1} \mathrm{G}$ iven the numbers above, a US $\$ 10$ million dollar expansion in flour milling will require 6 direct jobs, while a comparable expansion in fluid milk manufacturing will require 13. Multiplying the same jobs multiplier (6) to each number of new direct jobs created implies that 36 total jobs will be created in the economy as a result of the flour milling expansion versus 78 total jobs as a result of the fluid milk manufacturing expansion.
} 
approaches employed (e.g., Econsult Solutions \& Fox School of Business, 2018; Schmit, 2016; Deller, 2014; University of Arkansas, 2014; Fields, Guo, Hodges \& Mohammad, 2013; Ferris \& Lynch, 2013). Largely, such studies rely on existing secondary data and software regarding industry spending and sales patterns (often IMPLAN). ${ }^{2}$ Some recent commodity-specific examples include the U.S. dairy industry (International D airy Foods Association [ID FA], n.d.), the North American cranberry industry (Alston, Medellin-Azuara, \& Saitone, 2014), and the Washington State apple industry (Globalwise, 2014)--again, primarily relying on existing secondary data.

Alternatively, Schilling, Sullivan, Komar, and Marxen (2011) analyze the agritourism industry in New Jersey, one that is not defined explicitly in the North American Industry Classification System (NAICS); thus, an analysis of this industry requires supplemental data collection to identify its spending and sales patterns. ${ }^{3}$ Similarly, the economic contributions of cooperative businesses have been studied (e.g., Deller, Hoyt, Hueth, \& SundaramStukel, 2009; Karaphillis, D uguid, \& Lake, 2017). Since cooperatives are not confined to any one industry, researchers need to either identify the industries for which they are located and apply those sales and spending patterns to the cooperative activity, or collect data from cooperatives to quantify them explicitly.

Increasing discussions of agriculture-based economic development opportunities have occurred in the context of how expanding local food systems benefit agricultural producers and the local communities from where they reside. Alternative impact analyses have been applied to a range of local food system activities--e.g., direct marketing (Schmit, Jablonski, \& Mansury, 2016; Hughes \& Isengildina-Massa, 2015; Henneberry, Whitacre, \& Agustini, 2009; Hughes, Brown, Miller, \& McConnell, 2008, Otto \& Varner, 2005), food hubs (Jablonski, Schmit, \& Kay, 2016; Schmit \& Jablonski, 2017), farm-to-school (G unter \& Thilmany, 2012), and livestock processing
(Swenson, 2011). Thilmany McFadden et al. (2017) provide a comprehensive examination of these types of analyses and present a guiding toolkit to assist communities assessing these issues.

By better understanding the relationships of agricultural industries within local economies, community educators, industry leaders, and public officials can make more informed choices to enhance economic activity and impact. However, precise answers to these types of questions are elusive, often due to a lack of data to address them sufficiently. Accordingly, the evaluation of the economic contributions of industries and/ or industry expansion efforts requires careful consideration of the methodologies employed and data collected for their use.

We address these issues through three distinct yet inter-related contributions. First, the requirements and availability of appropriate data are of particular consequence to producing defensible economic impacts. Understanding where local primary data can supplement or replace secondary data is important in order to improve the precision of results. That said, primary data collection comes with a cost, in both time and dollars. Using the NYS apple industry as a case study, we describe the costs and rewards of primary data collection to support more refined and locally-specific impact estimates. We describe the nature of the financial data needed, highlight the costs of and potential barriers to collecting it, and compare economic contribution results based on the primary data we collected relative to the default data available in IMPLAN.

Second, we illustrate a framework for appropriately conducting multi-industry economic contribution analyses--specifically, where the outputs of some industries serve as inputs to others. For our case example of the apple industry, we go from farm input services, to farm production, to processing. Fruit production and processing are important agricultural industries in NYS, and apples represent a major component of these industries. However, our focus is less on the actual levels of

\footnotetext{
2 The IMPLAN economic impact assessment software system and associated data bases are often used by practitioners to construct local models and assess economic impacts. For more information, go to https:/ / www.implan.com

${ }^{3}$ For more information on NAICS industry categories go to https:/ / www.census.gov/ eos/ www/ naics/
} 
impact, but rather on the process and what practitioners need to consider to appropriately estimate economic contributions, avoid double counting, and interpret the results.

O ur final contribution emphasizes the distributional impacts associated with an industry's direct contributions. The indirect and induced changes in economic activity make up the multiplier effects via inter-industry purchases and supply chain linkages. The indirect impacts are in the form of purchases of a variety of goods and services in backwardlinked industries; the induced impacts are in the form of the labor income generated by those businesses and spent by owners and employees for household goods and services. Multipliers are a useful way to sum up the total value of industry linkages; however, much can be learned from a closer examination of the individual components of those values.

We continue now with a description of our analytical approach, including an exposition of what types of data were collected (primary and secondary) for our case study example and how we quantified the direct effects. We then present the results to the three contributions identified above. We close with a summary discussion and conclusions.

\section{Applied Research Methods}

Particular to this special issue of the journal, our approach incorporates all of the modules from Thilmany McFadden et al. (2017). In particular, we received input from industry stakeholders (e.g., New Y ork Apple Association (NYAA), NYS Cider Association) to frame our economic assessment (Module 1). We incorporated secondary data into our analysis from the U.S. D epartment of Agriculture (USD A), U.S. D epartment of the Treasury (USDT), and IMPLAN (Module 2).We developed and administered firm-level surveys for apple producers and intermediaries (Module 3 ) and engaged with additional stakeholders to supplement our primary data collection efforts (e.g., Cornell Cooperative Extension (CCE), the CCE Lake O ntario Fruit Team (LOFT), and Cornell University (Module 4). We constructed a customized state-level inputoutput (IO) model within IMPLAN. This model included a specific NYS apple farming industry extracted from the more aggregate fruit farming sector available in the software. We also accounted for product flows across industries to prevent double counting (Modules 5, 6, and 7).

IO models provide an insightful way to investigate the underlying processes that bind an economy together. Its strengths lie in a detailed representation of the primary and intermediate input requirements by production sector, the distribution of sales of individual industries throughout an economy, and the interrelationships among these industries and other economic sectors of an economy (Schmit \& Boisvert, 2014). O ur description of economic contributions follows three common economic measurements-- output, labor income, and employment. Output is the value of industrial production in producer prices; for manufacturing sectors, it equals sales plus changes in inventory; for service sectors, it equals sales; and for wholesale and retail sectors, it equals the gross margin (i.e., sales less the cost of goods sold). Labor income is the sum of employee compensation (i.e., total payroll cost) and proprietor income (i.e., income to self-employed and unincorporated business owners). Employment is the average monthly number of jobs in a year, both full and part-time.

\section{Contribution A nalysis}

In deference to an impact analysis that considers the change in new demand induced by policy or private initiatives, a contribution analysis for an industry (or collection of industries) describes that portion of an economy that can be attributed to the existing industry (or industries). For a contribution analysis, the existing total output provides the initial direct effects of the analysis. When compared to the entire economy, the results provide insight into the relative extent of the industry in the economy and the strength of its backward linkages. With respect to output, the direct effects represent sales by the industry or industries of interest, the indirect effects represent sales by the backwardlinked industries, and the induced effects represent industry sales due to consumption out of labor income.

A collection of related agriculture-based industries represents a complex intersection of production inputs and services at the farm to produce a 
crop that is subsequently harvested, processed, and marketed to a series of downstream intermediaries (e.g., wholesalers and retailers) and institutions (e.g., governments and households). In a multiindustry analysis, it is important to understand where outputs in one industry represent inputs to another to avoid double counting. IMPLAN provides procedures to accommodate this within their software; further explanations are available in Schmit (2016) and Schmit, Severson, Strzok, and Barros (2018). ${ }^{4}$

\section{Primary D ata C ollection}

When conducting an economic impact or contribution analysis in IMPLAN, it is important to consider when the existing industry parameters that represent its spending activities are sufficient for analysis and when those parameters should be updated through supplemental data collection. Production functions in IMPLAN--i.e., the spending on intermediate inputs and outlays to value added per dollar of output--represent national industry averages. Accordingly, these averages more closely reflect firms that contribute a relatively large proportion of total output to a sector (i.e., typically large firms). For example, a large fruit farm in Washington would have an identical production function as a small fruit farm in NYS. Given differences in climate, soils, crop varieties, and production practices, this is a difficult assumption to defend.

In addition, industries of interest may not be reported explicitly in existing secondary sources. They may, instead, be included within larger industry aggregates. Specific to our example, apple farming is included within the F ruit $F$ arming industry (industry 4) in IMPLAN. For NYS, other fruit farming primarily consists of grapes, but also some cherry and stone fruit production. The question of adequacy becomes even more acute in this case; i.e., is the national average production function for all fruit farming adequate for application to apple farming in NYS? Likely not.

To account for these problematic issues, we developed a financial survey for NYS apple producers and intermediaries (i.e., storage and distribution firms and apple processors) to collect localized data. ${ }^{5}$ Collecting detailed financial data from firms is time-consuming and difficult, particularly when it is not done in a face-to-face format to address hesitations and when it asks for data not normally collected and/ or recorded by firms (e.g., input purchases delineated by location). Accounting for input expenditures within IMPLAN also varies based on whether those purchases are from manufacturers, wholesalers, or retailers, therefore requiring a more complex financial survey. While we were able to adapt surveys from prior work, tailoring the surveys to match the industries of interest and mapping financial business categories to IMPLAN categories takes considerable time. Several weeks were required to develop the surveys, program them in online (Qualtrics) and written formats, and vet them with industry partners.

We worked with the NYAA to administer the surveys and reach out directly to firms through emails, web postings, social media, and in-person requests. Because survey respondents are busy, communicating any incentive for them to participate is critical. Notably, the farms and intermediaries in our case example contribute financially to NYAA through the state's apple marketing orders. Because the NYAA was planning to use the results for public and private marketing efforts, we thought this was a sufficient incentive to participate. It wasn't. Timing is also important. In hindsight, ours was poor; late summer to early fall was a busy time due to harvest preparation.

Several reminders were sent out and the survey deadline was extended, but with little result. Ultimately, our efforts were unsuccessful. O nly 25 of the roughly 600 commercial apple growers in the state responded to the survey. Less than one-half of those reported sales data, one-fifth reported input purchases, and one-sixth reported local purchase percentages. Ultimately, only four surveys were of use for our analysis, insufficient to produce

\footnotetext{
${ }^{4}$ Instructions for doing a multi-industry contribution analysis within IMPLAN are available at https:/ / implanhelp.zendesk.com/ hc/ en-us/ articles/ 115009542247-Multi-Industry-Contribution-Analysis-In-IMPLAN-Pro

${ }^{5}$ Copies of the surveys and more detail on the apple industry in NYS are available in Schmit et al. (2018).
} 
defensible financial profiles. By now months had passed.

We were extremely fortunate to discover additional resources. Routinely, the Lake O ntario Fruit Team (LOFT) collects financial data from apple farms they work with and summarizes it in the Fruit F arm Business Summary (FFBS) (LOFT, 2017). From this information, we created a representative apple farming production function for NYS. That said, the FFBS did not contain estimates of the percentage of input purchases made to firms within NYS. IMPLAN defines these percentages as "local purchase percentages" or "LPP." In our case, "local" was NYS. Accordingly, we needed to apply the LPP estimates within IMPLAN for the NYS study area. ${ }^{6}$

Given that the focus of our example was the apple industry in NYS and we believed the existing production function for fruit farming to be insufficient, we included the production function for apple farming as a separate industry in our IMPLAN model--i.e., by extracting apple farming from the preexisting fruit farming sector. D oing so implies that all sectors purchasing fruit from farmers must be edited to reflect a combination of apple fruit and non-apple fruit purchases. In our model example, 24 industries (of the 536 currently in IMPLAN) purchased fruit from farmers, as well as state and local governments and households. D isaggregating these purchases definitively across sectors would require surveying firms in all of the sectors that purchase fruit. This is a large task and one with an unnecessarily high cost to implement. Given that the total level of fruit purchases remained unchanged, changes in the allocation between apple fruit and non-apple fruit will have little effect on the overall model results. Accordingly, we allocated purchases of "fruit" to "apple fruit" and "non-apple fruit" based on their relative production values in the state. ${ }^{7}$

Responses by intermediaries to the financial survey were even poorer than for apple farms: only five surveys were returned. Very little financial data was reported and nothing of value was reported to adjust IMPLAN's default production function parameters. However, relative to apple farming, this was deemed less problematic. National average production functions were seen as sufficient as processors likely had similar production functions across geographic areas; further, the distribution of processors by size in NYS was similar to peer processing states. Since no apple-specific processing sectors are available within IMPLAN, we selected a set of fruit and vegetable processing sectors where apple-based products are prevalent. ${ }^{8}$

\section{D efining D irect E ffects}

In addition to evaluating the adequateness of an industry's sales and spending patterns, quantifying the level of the direct industry activity is required in economic contribution analyses--i.e., the direct effects. Economic impact analyses are based on a particular expansion scenario where the direct effects are defined internally-- e.g., a new manufacturing plant with an expected volume of sales or workers employed. For a contribution analysis, existing estimates of industry activity (e.g., output, jobs, and labor income) are used for the direct effect. IMPLAN carefully sources secondary data from a collection of federal, state, and local sources to compile their industry estimates. However, when an industry of interest is contained within a larger industry aggregate, additional effort is required of the researcher. O ther secondary data sources or primary data collection may be appropriate, depending on the nature of the industry. In our example, seven industry sectors were included: (i) agricultural support services, (ii) nursery stock, (iii) farming, (iv) frozen, canned, and dehydrated processing, (v) hard cider and wine processing, (vi) industry marketing, and (vii) industry public research and extension.

\footnotetext{
${ }^{6}$ An example here may be useful. Consider two apple farms in NYS, Farm A and Farm B. They both purchase $\$ 0.10$ of fertilizer to grow their crop for every dollar of apples sold. However, Farm A purchases the fertilizer from local supply store in NYS, while Farm B purchases the fertilizer from a supply store in Pennsylvania. Farm A's fertilizer purchases contribute to economic impacts in NYS, while Farm B's does not. In the latter case, this spending is referred to as leakage, as the spending leaves the defined local region, NYS in our example.

${ }^{7}$ D etailed instructions for creating a new sector in IMPLAN are available in Schmit \& Jablonski (2017).

${ }^{8}$ For more details, see Schmit et al. (2018).
} 


\section{Results}

The results presented here represent both the intermediate and final results of our apple industry application. Through the discussion, our ambition is to help practitioners understand what an economic contribution analysis is, when it is used, and what it can tell you.

Q uantified D irect E ffects

The direct effects for output and employment for each apple industry are shown in Table 1. While the level of effects is of less interest in this paper, the table also highlights the data sources for each industry and where the production functions and LPPs are defined. To improve understanding of our empirical process for broader application to these types of studies, we summarize below the integration of data sources by industry and the IMPLAN industries to which they apply. Additional details are available in Schmit et al. (2018).

Agricultural Support Services: Support activities for apple farming fall under Support A ctivities for A griculture \& F orestry industry (19) in IMPLAN. The direct effect is computed as a proportion of total industry sales in (19) based on the ratio of apple farming to total farming output in NYS.
Employment follows by applying IMPLAN's jobs to output ratio for (19). The production function for (19) and LPPs in IMPLAN were utilized.

N ursery Stock Suppliers: Economic activity associated with nursery stock suppliers is included in $G$ reenhouse, $N$ ursery, \& Floriculture industry (6) in IMPLAN. The LOFT provided an estimate of one million trees produced per year at a value of US\$7/ tree. The production function for (6) and LPPs in IMPLAN were utilized.

Apple farming: The USD A's value of production for apple farming in NYS was used as the measure of output (USD A National Agricultural Statistics Service [USDA NASS], 2017). Employee compensation from FFBS (LOFT, 2017) was combined with IMPLAN's compensation per worker for the fruit farming industry (4) to estimate total jobs. IMPLAN's LPPs were utilized for the industry's input purchases.

\section{Frozen, Canned, \& Dehydrated Processing:} Most NYS processed apple products (e.g., frozen concentrate, juices, jellies, slices) fall under IMPLAN's F ruit \& V egetable Frozen, Canned, \& D ehydrated Products Manufacturing industries (79, 81,

Table 1. Level of Direct Effects and Sources of Data, New York Apple Industry, 2016 Dollars

\begin{tabular}{lccccc}
\hline & $\begin{array}{c}\text { Direct } \\
\text { Employment } \\
\text { (jobs) }\end{array}$ & $\begin{array}{c}\text { Direct } \\
\text { Output } \\
\text { (US\$ million) }\end{array}$ & Direct Effect & $\begin{array}{c}\text { Production } \\
\text { Function }\end{array}$ & $\begin{array}{c}\text { Local Purchase } \\
\text { Percentages }\end{array}$ \\
\hline Apple agricultural support services (19) & 265 & 11.9 & IMPLAN & IMPLAN & IMPLAN \\
\hline Apple nursery stock (6) & 81 & 7.1 & LOFT & IMPLAN & IMPLAN \\
\hline Apple farming (7) & 5,605 & 317.0 & USDA & LOFT & IMPLAN \\
\hline $\begin{array}{l}\text { Apple processing: frozen, canned, \& } \\
\text { dehydrated (79, 81, \& 83) }\end{array}$ & 1,635 & 838.8 & $\begin{array}{c}\text { IMPLAN } \\
\text { USDA }\end{array}$ & IMPLAN & IMPLAN \\
\hline $\begin{array}{l}\text { Apple processing: apple wine } \& \text { hard cider } \\
\text { (109) }\end{array}$ & 425 & 129.8 & NCGA & IMPLAN & IMPLAN \\
\hline Apple industry marketing (457) & 6 & 3.1 & NYAA & IMPLAN & IMPLAN \\
\hline Apple public research \& extension (456) & 16 & 2.2 & CU & IMPLAN & IMPLAN \\
\hline Total & 8,033 & $1,309.9$ & & &
\end{tabular}

Source: Schmit, et al (2018). LOFT = Lake Ontario Fruit Team, Cornell Cooperative Extension, USDA = United States Department of Agriculture, NCGA = Nielsen Commercial Grocers Association (Brager and Crompton, 2017), USDT = United States Department of the Treasury, Alcohol and Tobacco Tax and Trade Bureau, NYAA = New York Apple Association, CU = Cornell University, Office of Sponsored Programs, CCE = Cornell Cooperative Extension. 
and 83 , respectively). ${ }^{9}$ We estimated output and employment as $45 \%$ of the totals contained in these industries (Schmit et al., 2018). IMPLAN production functions and LPPs were utilized.

\section{Hard Cider and Apple Wine Processing: Hard} (alcoholic) cider, applejack, and apple wines fall under W ineries industry (109) in IMPLAN. Retail cider prices from Nielsen CGA (Brager \& Crompton, 2017) were used in concert with Alcohol and Tobacco Tax and Trade Bureau cider volume data to estimate the value of total output (USDT, 2018). The production function for (109) and LPPs in IMPLAN were utilized.

Industry Marketing: Industry marketing is conducted by the NYAA. They provided income, expense, and employment data to us; however, the expense categories were too aggregated and thus could not be mapped to IMPLAN and LPPs. Their activity falls under A dvertising, Public Relations \&
Related Services industry (457) in IMPLAN. The production function for (457) and LPPs in IMPLAN were utilized.

Industry Public Research \& Extension: Cornell University's O ffice for Sponsored Programs (O SP) provided data on outside grants awarded over the previous five years related to apple industry research. Average annual funding was computed. In addition, CCE provided data on expenditures and employment for apple industry extension efforts. Both activities fall within the Scientific Research \& D evelopment Serviœs industry (456) in IMPLAN. The production function for (456) and LPPs in IMPLAN were utilized.

Comparing Production F unctions

O ur NYS apple farming production function was constructed to include 24 input purchase and four value added categories. For ease of exposition, we provide a summary of those results in Table 2 and

Table 2. Apple Farming Production Function in New York State Compared to Fruit Farming Production Function in IM PLAN

\begin{tabular}{lcccc}
\hline Industry/ Value Added Aggregate & $\begin{array}{c}\text { Fruit Farming } \\
(\text { IMPLAN) }\end{array}$ & Apple Farming (NYS) $^{\mathrm{a}}$ & Difference $^{\mathrm{a}}$ & $\begin{array}{c}\text { Percent } \\
\text { Difference }\end{array}$ \\
\hline Ag \& ag support services & 0.0552 & 0.0353 & -0.0199 & $-36 \%$ \\
Utilities & 0.0037 & 0.0054 & 0.0017 & $47 \%$ \\
Construction & 0.0032 & 0.0131 & 0.0099 & $310 \%$ \\
Manufacturing & 0.0256 & 0.1094 & 0.0838 & $327 \%$ \\
Wholesale trade & 0.0042 & 0.0790 & 0.0748 & $1776 \%$ \\
Retail trade & 0.0001 & 0.0042 & 0.0042 & $5200 \%$ \\
Transportation \& warehousing & 0.0020 & 0.0240 & 0.0220 & $1123 \%$ \\
Information & 0.0003 & 0.0027 & 0.0024 & $841 \%$ \\
Finance \& insurance & 0.0063 & 0.0282 & 0.0219 & $347 \%$ \\
Real estate \& rental & 0.0026 & 0.0309 & 0.0284 & $1103 \%$ \\
Professional services (non-ag) & 0.0022 & 0.0641 & 0.0619 & $2833 \%$ \\
$\quad$ Total intermediate inputs & 0.10524 & 0.3962 & 0.2909 & $276 \%$ \\
Employee compensation & 0.2975 & 0.3266 & 0.0292 & $10 \%$ \\
Proprietor Income & 0.2616 & 0.1806 & -0.0810 & $-31 \%$ \\
Other property type income & 0.3216 & 0.0876 & -0.2340 & $-73 \%$ \\
Taxes on production \& imports & 0.0141 & 0.0090 & -0.0051 & $-36 \%$ \\
Total value added & 0.8948 & 0.6038 & -0.2909 & $-33 \%$ \\
\hline
\end{tabular}

Sources: IMPLAN (2016) and author calculations.

a Dollars of expenditure or outlay per dollar of output.

${ }^{9}$ For detailed information on commodities produced within IMPLAN industries, see https:/ / implanhelp.zendesk.com/ hc/ enus/ articles/ 115009674428-IMPLAN-Sectoring-NAICS-Correspondences 
compare them to the default estimates provided in IMPLAN for fruit farming (4). ${ }^{10}$ The parameters in the first three columns represent expenditures per dollar of output, while the final two columns represent the absolute and percentage differences for the apple farming estimates, respectively, relative to those within IMPLAN.

Looking first at the allocations between total intermediate inputs and total value added, it is clear that there are considerable differences between production functions. In fruit farming, around 10\% of every dollar of output goes to purchase intermediate inputs, while $90 \%$ goes to one of four categories of value added. The comparable numbers for the apple farming industry we constructed are $40 \%$ and $60 \%$, respectively. The absolute level of these aggregated category differences alone is strong support that the default production function in IMPLAN was inadequate for our analysis.

More intermediate inputs are required for apple farming in NYS. In terms of expenditures per dollar of output, this is particularly true for purchases from manufacturers $(+0.084)$, wholesalers (+0.075), and non-ag (e.g., accounting, legal)

Table 3. Economic Contributions for Apple Farming with AuthorConstructed Production Function and IMPLAN's Fruit Farming Production Function

\begin{tabular}{lccc}
\hline Impact Type & $\begin{array}{c}\text { Employment } \\
\text { (Jobs) }\end{array}$ & $\begin{array}{c}\text { Labor Income } \\
\text { (US\$ Million) }\end{array}$ & $\begin{array}{c}\text { Output } \\
\text { (US\$ Million) }\end{array}$ \\
\hline Direct Effect & 5,605 & 164.7 & 317.0 \\
Indirect Effect & 525 & 40.6 & 116.0 \\
Induced Effect & 886 & 52.1 & 141.0 \\
\cline { 2 - 4 } Total Effect & 7,016 & 257.4 & 574.0 \\
\hline \multicolumn{4}{c}{ IM PLAN Fruit Farming Production Function (Default) } \\
\hline Direct Effect & 6,388 & 181.6 & 317.0 \\
Indirect Effect & 244 & 9.9 & 23.3 \\
Induced Effect & 832 & 49.0 & 132.4 \\
Total Effect & 7,464 & 240.5 & 472.7 \\
\hline \multicolumn{4}{c}{ Percentage Change with Primary Data } \\
\hline Total Effect & -6.01 & +7.09 \\
\hline
\end{tabular}

Sources: IMPLAN (2016), Author calculations.

Note: Both models defined by the same direct effect for output (US\$317.0 million). professional services (+0.062). However, apple farms in NYS purchased less ag support services and products from other farmers (-0.020). The degree to which such differences affect the contribution results will depend on how different the supply industries are and the degree to which those industries are local.

Outlays per dollar of output for proprietor income (PI) and other property type income (O PTI, largely corporate profits) are much lower for the NYS apple farming industry estimates relative to IMPLAN's fruit farming industry estimates (i.e., $-31 \%$ and $-73 \%$, respectively). While a lower outlay to PI will reduce economic contributions, since it is a component of labor income, a lower outlay to OPTI will not since it does not contribute to economic impact (e.g., we do not know if corporate profits are distributed locally). Because the reduction in proprietor income $(-0.0810)$ is more than the increase in employee compensation $(+0.0292)$, the contribution result from these two categories will be less than that in the default case.

To understand the overall difference in results by using localized data, we conducted single industry contribution analyses for apple farming using the default fruit farming production function in IMPLAN and the apple farming production function we constructed. Since IMPLAN's LPPs for inputs were used in each case, the only differences arising from the LPPs will come from the degree to which different supplying industries have different LPPs. We start with the same direct output effect in each case, US $\$ 317$ million. The results are shown in Table 3. The change in total output was over $21 \%$ higher when using the production function we constructed (i.e., US\$574.0 versus US\$472.7 million). This was largely a consequence of the higher level of intermediate

10 The fully detailed production function is found in Schmit et al. (2018), page 56. 
input purchases. This is reflected explicitly in the difference in the levels of indirect effects (i.e., US $\$ 116.0$ versus US\$23.3 million).

The overall change in labor income was also positive, around $7 \%$ (i.e., US\$257.4 versus US\$240.5 million). This change was much lower than output since the initial direct effect in apple farming was lower to begin with (i.e., US\$164.7 versus US\$181.6 million). Recall, the combined change in employee compensation and proprietor income from Table 2 is negative. The overall gain is again due to the higher level of indirect effects for apple farming (i.e., US\$40.6 versus US\$9.9 million). The negative effect on total jobs is due solely to the lower number of initial direct jobs for our constructed industry--i.e., the indirect and induced effects on jobs are higher for apple farming.

Multi-Industry E conomic C ontribution

Table 4 presents the results of the multi-industry analysis. We include results for both the individual industries and the total across all industries. Individual industry contributions allow for a detailed accounting of their specific indirect and induced

Table 4. Economic Contribution of the Apple Industry in New York, by Sector, 2016

\begin{tabular}{|c|c|c|c|c|c|}
\hline Category and Sector & $\begin{array}{l}\text { Direct } \\
\text { Effecta }\end{array}$ & $\begin{array}{c}\text { Indirect } \\
\text { Effectb }\end{array}$ & $\begin{array}{c}\text { Induced } \\
\text { Effectc }\end{array}$ & $\begin{array}{l}\text { Total } \\
\text { Effect }\end{array}$ & $\begin{array}{c}\text { Contribution } \\
\text { Multiplierd }\end{array}$ \\
\hline \multicolumn{6}{|c|}{ Output (US\$ million) } \\
\hline Agricultural support services & 11.9 & 1.6 & 5.7 & 19.2 & 1.62 \\
\hline Nursery stock suppliers & 7.1 & 0.6 & 2.9 & 10.6 & 1.49 \\
\hline Farming & 317.0 & 116.0 & 141.0 & 574.0 & 1.81 \\
\hline Processing (frozen canned, dehydrated) & 838.8 & 318.5 & 149.8 & $1,307.1$ & 1.56 \\
\hline Processing (hard cider, apple wine) & 129.8 & 52.9 & 36.2 & 218.9 & 1.69 \\
\hline Industry marketing & 3.1 & 0.8 & 1.2 & 5.2 & 1.65 \\
\hline Industry public research \& extension & 2.2 & 1.1 & 0.3 & 3.6 & 1.65 \\
\hline Total & $1,309.9$ & 441.3 & 314.3 & $2,065.5$ & 1.58 \\
\hline \multicolumn{6}{|l|}{ Employment } \\
\hline Agricultural support services & 265 & 7 & 36 & 308 & 1.16 \\
\hline Nursery stock suppliers & 81 & 5 & 18 & 104 & 1.28 \\
\hline Farming & 5,605 & 525 & 886 & 7,016 & 1.25 \\
\hline Processing (frozen canned, dehydrated) & 1,635 & 1,441 & 940 & 4,016 & 2.46 \\
\hline Processing (hard cider, apple wine) & 425 & 252 & 228 & 905 & 2.13 \\
\hline Industry marketing & 6 & 5 & 8 & 19 & 3.19 \\
\hline Industry public research \& extension & 16 & 6 & 2 & 24 & 1.49 \\
\hline Total & 8,033 & 1,849 & 1,989 & 11,872 & 1.48 \\
\hline \multicolumn{6}{|l|}{ Labor Income (US\$ million) } \\
\hline Agricultural support services & 7.7 & 0.5 & 2.1 & 10.4 & 1.34 \\
\hline Nursery stock suppliers & 4.0 & 0.2 & 1.1 & 5.3 & 1.33 \\
\hline Farming & 164.7 & 40.6 & 52.1 & 257.5 & 1.56 \\
\hline Processing (frozen canned, dehydrated) & 106.9 & 113.8 & 55.4 & 276.0 & 2.58 \\
\hline Processing (hard cider, apple wine) & 31.5 & 21.1 & 13.4 & 66.0 & 2.10 \\
\hline Industry marketing & 1.5 & 0.3 & 0.5 & 2.3 & 1.52 \\
\hline Industry public research \& extension & 0.8 & 0.5 & 0.1 & 1.4 & 1.71 \\
\hline Total & 317.2 & 154.8 & 115.9 & 587.9 & 1.85 \\
\hline
\end{tabular}

Source: Schmit et al. (2018)

a Direct effects represent total activity (sales, employment, labor income, value added) by the respective industry.

$b$ Indirect effects represent all activity by the backward-linked supply chain industries.

c Induced effects represent additional industry activity due to consumption out of labor income.

${ }^{d}$ The contribution multiplier is calculated as the total effect divided by the direct effect. 
effects. They also reflect industry linkages with both non-apple industries and other apple industries. Separate contribution analyses in IMPLAN must be conducted for each industry category.

Total economic contributions (i.e., the direct, indirect, and induced effects) of the entire apple industry in NYS are US\$2.1 billion in output, US\$587.9 million in labor income, and 11,872 jobs. Computing contribution multipliers as the total effect divided by the direct effect, we find that for every dollar of output, dollar of labor income, and job in the apple industry in NYS, US $\$ 0.58$ of output, US\$0.48 of labor income, and 0.85 jobs are supported in non-apple industries in NYS.

Important to the interpretation in Table 4, the direct effects across industry sectors are additive (i.e., the seven individual values sum up to the total), but the indirect and induced effects across industry sectors are not. For example, when looking at the frozen, canned, and dehydrated processing sector output contributions, a portion of the US\$318.5 million in indirect effects is the value of apple sales from farming through processor purchases of local apples. In other words, a portion of the indirect effects for processing is already included in the direct effects for farming. Summing the individual industry indirect and induced impacts would result in double counting. Indeed, part of the multiplier effects for each individual industry includes any other apple industries backward linked to them. The contribution multipliers for the aggregate industry, however, reflect only non-apple industry backward linkages.

\section{E x ploring Back ward L ink ages}

In addition to understanding the total economic contributions of industries, it is useful to examine what industries contribute most heavily to those totals via backward industry linkages. D epending on the objectives of the research, examining the distribution of linkages for each industry, as well as for the aggregate, may be important. For ease of exposition, we focus our discussion on the aggregate industry results from our application.

Figure 1 displays the distribution of the total indirect and induced output effects from Table 4 (i.e., US\$441.3 and US\$314.3 million) generated by the apple industry's combined direct output effect
(US\$1,309.9 million). In other words, the sum of the height of each bar in Figure 1 will equal the total indirect and induced effects shown in Table 4 for the aggregate apple industry. For ease of exposition, the industries are aggregated to the 2-digit NAICS level. The figures present a visual form of how the indirect and induced effects accumulate and to which industries they accrue.

The indirect effects are shown in black, and the induced effects are shown in gray. Considering the indirect effects more closely is useful in understanding the business-to-business linkages originating from an industry's direct activities. In deference, industry activity incurred by spending out of labor income (i.e., the induced effect) is invariant to the industry of origin. Accordingly, the interpretation and discussion highlight the indirect industry effects.

In our example, wholesale trade has the strongest backward linkages for the apple industry-i.e., it has the highest bar in Figure 1. This makes intuitive sense as many input purchases by farms, processors, and other apple sectors are from local wholesale distributors, rather than from retail establishments. Not surprisingly, most of the impact to wholesale trade is derived from indirect effects--i.e., the black portion of the bar is larger than the gray portion of the bar. Manufacturing firms have the next highest level of linkages, almost entirely from local business-to-business (indirect) linkages.

As indicated by the first bar in Figure 1, apple industry firms purchase a relatively small volume of inputs from other (non-apple) farm production sectors. Their inputs are primarily non-apple fruits and vegetable purchases from farms and manufacturers for processing and/ or resale. O ther business support sectors, such as transportation and warehousing, finance and insurance, and contracted professional services make up the bulk of the remaining indirect effects.

The largest induced effects follow intuitively from major household budget allocations--i.e., insurance, real estate, healthcare, dining, and various retail purchases. D istributions of backward linkages by industry can be similarly constructed for employment and labor income if desired. While the general takeaways will be similar, the variation 
Figure 1. Indirect and Induced Output Effects by Industry for New York State Apple Industry from the US\$1,309.9 Million Direct Effect



across industries will vary due to differences in labor use by industry and/ or employee compensation.

\section{Discussion and Conclusions}

Improving the understanding of intra- and interindustry linkages within local economies is necessary for community educators, industry leaders, and public officials to make informed choices regarding agriculture-based economic development priorities and the projected impacts on economic growth and community goals. More recently, the focus has shifted to how improvements in or expansions of local and regional food systems can generate these desired impacts. A careful consideration of the methodologies to employ and data to collect are necessary to produce meaningful and defendable results.

In this paper, we highlight the application of best practices from Thilmany et al. (2017) to address agricultural industry interest in describing the nature of their economic contributions to local economies. In particular, we apply a multi-industry economic contribution analysis to the apple industry in NYS. We identify seven key individual industries within the broader apple industry collective and describe the process from inception to application to interpretation. As these types of analyses are popular, among industry and public agencies alike, promoting a replicable framework will improve the compatibility and comparison of analyses across industries, geographies, and time.

Our multi-industry application identified conditions where primary, localized data collection was needed relative to reliance on industry average parameters. With our specific application to the apple farming industry in NYS, we were able to document that relying on more aggregate industry 
relationships from secondary data sources biased downward total economic contributions (i.e., direct, indirect, and induced) for output and labor income, but biased upward total jobs. In all cases, however, reliance on pre-existing secondary estimates in our application biased downward the level of indirect and induced effects.

One cannot predict a priori whether future impact or contribution results will be higher or lower when collecting and utilizing primary data, but that's not the point. The point is that the results will be more accurate and defensible. In addition, constructing localized industry production functions provides specific information regarding the nature of the backward linkages and indirect industry effects, even before the IO model is constructed. That said, data collection comes with a cost and the efforts to plan and budget (in time and dollars) for such activities cannot be understated. When budgets are slim and/ or time is tight, primary data collection may be infeasible, requiring the analysis to be done with existing resources and data. D epending on the objectives of a given study, using pre-existing resources may be sufficient. In any case, clearly documenting the inputs, assumptions, and analytical processes is key to a comprehensive analysis and to understanding the limitations of the results.
Often in multi-industry contribution analyses, outputs from some industries represent inputs to others. Practitioners need to adequately understand where supply chain linkages occur and how to account for them to avoid double counting. In this paper, we highlighted existing resources available to assist practitioners in these efforts and explained the processes advocated in them with our application to the apple industry. In doing so, the actual empirical results we present are less important than the process we used to get to them.

Multipliers, while useful, are often relied on too heavily in decision making and without an understanding of their construction, interpretation, and context. O ur empirical application describes the construction of our contribution estimates and the multipliers accruing to them. In particular, we highlight the individual industry contributions that lead to a composite multiplier result. In doing so, particularly through the indirect effects, practitioners can better understand local supplying industries that are most important to the industry of inquiry and, therefore, most influenced by related industry expansions or contractions. Such an approach provides a useful way to describe economic contribution results and the composition of multiplier effects to a range of audiences.

\section{References}

Alston, J. M., Medellin-Azuara, J., \& Saitone, T. L. (2014). E cnomic impad of the N orth A merican cranberry industry. D epartment of Agricultural \& Resource Economics, University of California D avis. Retrieved from https:// watershed.ucdavis.edu/ library/ economic-impact-north-american-cranberry-industry

Brager, D., \& Crompton, M. (2017, A pril). U .S. cider trends: Increasing your odds of sucoess by evaluating mark etplace dynamics. Presentation at CiderCon conference, Chicago. Retrieved from https:/ / ciderassociation.org/ cider-trends-in-the-u-s/

Deller, S. (2014). Contribution of agriculture to the W isconsin economy: U pdated for 2012. D epartment of Agricultural \& Applied Economics, University of Wisconsin Madison. Retrieved from https:/ / trinaty.aae.wisc.edu/ wfp/wpcontent/ uploads/ sites/ 9/ 2014/ 09/ Impact-of-A griculture-2012-FINAL.pdf

Deller, S., Hoyt, A., Hueth, B., \& Sundaram-Stukel, R. (2009). Research on the economic impact of cooperatives. Madison: University of Wisconsin Center for Cooperatives. Retrieved from http:/ / reic.uwcc.wisc.edu/ sites/ all/ REIC_FINAL.pdf

Econsult Solutions \& Fox School of Business. (2018). Pennsylvania agriculture: A look at the economic impact and future trends. Pennsylvania Department of Agriculture. Retrieved from https:/ / econsultsolutions.com/ wpcontent/ uploads/ 2018/ 06/ TEAM-PA-AGRICULTURE-FINAL-REPORT.pdf

Fields, D ., Guo, Z., Hodges, A. W., \& Mohammad, R. (2013). E conomic impacts of A labama's agricultural, forestry, and related industries. Auburn, Alabama: D epartment of Agricultural Economics and Rural Sociology, Auburn University. Retrieved from http:// www.aces.edu/ pubs/ docs/ A/ ANR-1456/ ANR-1456.pdf 
Ferris, J. \& Lynch, L. (2013). Policy A nalysis Report: The impact of agriculture on Maryland's economy. College Park: D epartment of Agricultural and Resource Economics, University of Maryland. Retrieved from http:/ / agresearch.umd.edu/ sites/ agresearch.umd.edu/ files/ docs/ programs/ canrp/ Value\%200f\%20Ag\%20Report\%20.pdf

Globalwise, Inc. (2014). The W ashington apple industry: U pdated evaluation of contributions to the state economy and the important role of ex ports. Retrieved from https:/ / wstfa.org/ wstfa-assets/ uploads/ Economic-Impact-Study.pdf

Gunter, A., \& Thilmany, D . (2012). Economic implications of farm to school for a rural Colorado community. Rural Connections, 6, 13-16. Retrieved from https:/ / wrdc.usu.edu/ files-ou/ publications/ pub 9857945.pdf

Henneberry, S. R., Whitacre, B., \& Agustini, H. N. (2009). An evaluation of the economic impacts of O klahoma farmers markets. Journal of F ood D istribution R esearch, 40(3), 64- 78. Retrieved from http:/ / ageconsearch.umn.edu/ record/ 99760/ ?!n=en

Hughes, D. W., Brown, C., Miller, S., \& McConnell, T. (2008). Evaluating the economic impact of farmers' markets using an opportunity cost framework. Journal of A gricultural and A pplied E conomics, 40(1), 253-265. https:/ / doi.org/ 10.1017/ S1074070800028091

Hughes, D. W. \& Isengildina-Massa, O . (2015). The economic impact of farmers' markets and a state level locally grown campaign. Food Policy, 54, 78-84. https:/ / doi.org/ 10.1016/j.foodpol.2015.05.001

IMPLAN. (2016). New York State IMPLAN data (model year 2014) and modeling software. Huntersville, North Carolina.

International Dairy Foods Association (ID FA). (n.d.). D airy D elivers ${ }^{\circledR}$ : The economic impact of dairy products. Washington, D.C. Retrieved in 2017 from https:/ / www.idfa.org/ resources/ dairy-delivers

Jablonski, B. B. R., Schmit, T. M., \& Kay, D . (2016). Assessing the economic impacts of food hubs on regional economies: A framework that includes opportunity costs. A gricultural and Resourœ E conomics Review, 45(1), 143-172. https:// doi.org/ 10.1017/ age.2016.9

Karaphillis, G., D uguid, F., \& Lake, A. (2017). Economic impact of the Canadian co-operative sector (2009 and 2010). International Journal of Social E conomics, 44(5), 643-652. https:/ / doi.org/ 10.1108/ IJSE-09-2015-0225

Lake O ntario Fruit Team (LOFT). (2017). F ruit farm business summary: 2015. Ithaca, New Y ork: Cornell Cooperative Extension, Cornell University.

Otto, D ., \& Varner, T. (2005). C onsumers, vendors, and the economic importanœ of Iowa farmers' mark ets: A n economic impact survey analysis. Ames Leopold Center for Sustainable Agriculture, Iowa State University. Retrieved from https:/ / lib.dr.iastate.edu/ leopold_pubspapers/ 145/

Schilling, B. J., Sullivan, K. P., Komar, S., \& Marxen, L. J. (2011). The economic contributions of agritourism in N ew Jersey (Bulletin E333). New Brunswick, NJ: Rutgers University. Retrieved from https:/ / sustainable-farming.rutgers.edu/ wp-content/ uploads/ 2014/ 09/ The-Economic-Contributions-of-A gritourism-in-New-Jersey-e333.pdf

Schmit, T. M. (2016). The economic contributions of agriaulture in N ew Y ork State (2014) (EB 2016-09). Ithaca, NY: Charles H. Dyson School of Applied Economics and Management, Comell University. Retrieved from http:/ / publications.dyson.cornell.edu/ outreach/ extensionpdf/ 2016/ Cornell-D yson-eb1609.pdf

Schmit, T. M. \& Boisvert, R. N. (2014). A griculture based economic development in N ew Y ork State: A ssessing the inter-industry link ages in the agricultural and food system (EB 2014-03). Ithaca, NY: Charles H. Dyson School of Applied Economics and Management, Cornell University. Retrieved from http:/ / publications.dyson.cornell.edu/ outreach/ extensionpdf/ 2014/Cornell-D yson-eb1403.pdf

Schmit, T. M. \& Jablonski, B. B. R. (2017). A praditioner's guide to conducting an economic impad assessment of regional food hubs using IM PL A N : A systematic approach (EB 2017-01). Ithaca, NY: Charles H. D yson School of Applied Economics and Management, Cornell University. Retrieved from http:/ / publications.dyson.cornell.edu/ outreach/ extensionpdf/ 2017/ Cornell-Dyson-eb1701.pdf

Schmit, T. M., Jablonski, B. B. R., \& Mansury, Y. (2016). Assessing the economic impacts of local food system producers by scale: A case study from New York. E conomic D evelopment Q uarterly, 30(4), 316-328. https:/ / doi.org/ 10.1177\%2F0891242416657156

Schmit, T. M., Severson, R. M., Strzok, J., \& Barros, J. (2018). E conomic ontributions of the apple industry supply chain in N ew Y ork State (EB 2018-03). Ithaca, NY: Charles H. Dyson School of Applied Economics and Management, Cornell University. Retrieved from https:/ / dyson.cornell.edu/ outreach/ extension-bulletins/ documents/Cornell-Dysoneb1803.pdf 
Swenson, D . (2011). E x ploring small-scale meat processing ex pansions in Iowa. Ames: Leopold Center for Sustainable Agriculture, Iowa State University. Retrieved from https:/ / lib.dr.iastate.edu/ cqi/ viewcontent.cci?article=1091\&context=leopold pubspapers

Thilmany McFadden, Conner, D ., D eller, S., Hughes, D., Meter, K. ... Tropp, D . (2017). The economics of local food systems: A toolk it to guide community discussions, assessments, and choios. U.S. D epartment of Agriculture, Agricultural Marketing Service. Retrieved from https:/ / www.ams.usda.gov/ publications/ content/ economics-local-food-systems-toolkitguide-community-discussions-assessments

U.S. D epartment of Agriculture, National Agricultural Statistics Service [USD A NASS]. (2017). 2016- 2017 agricultural statistics annual bulletin: N ew Y ork. Retrieved from https:/ / www.nass.usda.gov/ Statistics by_State/ New_York/ Publications/Annual_Statistical_Bulletin/2017/ 2016-2017\%20NY\%20Annual\%20Bulletin.pdf

U.S. D epartment of the Treasury [USDT]. (2018, April 27). M onthly Statistical Report - W ine: Summary Calendar Y ear 2017. Alcohol and Tobacco Tax and Trade Bureau, Washington, D .C. Retrieved from https:/ / www.ttb.gov/ statistics/2017/ final17wine.pdf

University of Arkansas. (2014). E conomic contribution of A rkansas agrialture. Retrieved from https:// division.uaex.edu/docs/Economic_Contribution_2014.pdf 